\title{
Multiple Myxomas in Right Ventricle - A Case Report of Carney's Syndrome
}

\author{
NILUFAR FATEMA ${ }^{1}$, SHEIKH FOYEZ AHMED ${ }^{1}$, NAZIM AL AZAD ${ }^{2}$, MAFTAHUL JANNAT $^{3}$, MD. AZIZUL \\ HAQUE $^{3}$, MD. TAUHIDUL ISLAM ${ }^{4}$, MD. ABU SIDDIQUE ${ }^{1}$, SAJAL KRISHNA BANERJEE ${ }^{1}$, AKM FAZLUR \\ RAHMAN $^{1}$, SYED ALI AHSAN ${ }^{1}$, CHOUDHURY MESHKAT AHMED ${ }^{1}$, \\ MD. SHAFIUDDIN ${ }^{1}$, MD. HASIRUL HAQUE ${ }^{1}$,
}

${ }^{1}$ Department of Cardiology, Bangabandhu Sheikh Mujib Medical University (BSMMU), ${ }^{2}$ Department of Internal Medicine, BSMMU. ${ }^{3}$ Department of Neurology, BSMMU, ${ }^{4}$ Department of Rheumatology, BSMMU.

Address of Correspondence: Nilufar Fatema, Consultant, Department of Cardiology, Bangabandhu Sheikh Mujib Medical University, Dhaka, E-mail: nilufar.fatema@gmail.com

\section{Introduction:}

Myxoma is common cardiac tumor in left atrium and on the inter atrial septum but $8 \%$ cases of myxoma may be found in other chambers of heart. It may involve in cardiac valve. ${ }^{1}$ Right ventricular inflow or outflow obstructions, heart failure, embolization ${ }^{2}$ and arrhythmia are the common complications in myxoma case. If we can diagnose the case earlier then patient can be treated by operation under cardiopulmonary bypass. Thus one can avoid the complications. We report a rare case of a middle aged young female with multiple myxomas in right ventricle without any obstructing features.

\section{Case report:}

A young female, Mrs. Momtaz Begum, 30 years of age, was admitted to Bangabandhu Sheikh Mujib Medical University with the complains of palpitation and shortness of breath for 2 weeks. On examination, her temperature was raised, mildly anaemic, pulse was 90 BPM, BP was $80 / 60 \mathrm{~mm}$ of $\mathrm{Hg}$, clubbing- present, Jaundice- mild, oedema-mild, JVP not raised, Heart sounds: S1 was normal but Pulmonary component of S2 was loud. Pan systolic murmur in left parasternal region which has no radiation, SpO2 was 98, Lung base are clear. She was nondiabetic, ESR was high $\left(80 \mathrm{~mm}\right.$ in $1^{\text {st }}$ hour), her creatinine level was $2.5 \mathrm{mg} / \mathrm{dl}$, Urea was $81 \mathrm{mg} /$ dl. Sonography of Abdomen showed features suggestive of congestive cardiac failure and chronic renal failure. Her ECG revealed P-pulmonary, RVH with strain and RBBB, Doppler echocardiography showed dilated right atrium and right ventricle, two separate myxomas in right ventricle. One is globular in shape, well circumscribed non homogenous, measuring about 27mm X 29 mm, freely to and fro movement, has peduncle attached to infundibulum. Another is elongated in shape, measuring about $45 \mathrm{~mm}$ X $21 \mathrm{~mm}$, adhered to RV free wall and which extend upto right ventricular outflow. But Pulmonary valve velocity was $0.88 \mathrm{~cm} / \mathrm{sec}$ and PPG was $2.24 \mathrm{~mm}$ of $\mathrm{Hg}$. So there is no right ventricular outflow tract obstruction. And right sided inflow velocity was also normal. Moderate Tricuspid regurgitation was present. Calculated PASP was $80 \mathrm{~mm}$ of $\mathrm{Hg}$ and PADP was $35 \mathrm{~mm}$ of $\mathrm{Hg}$.

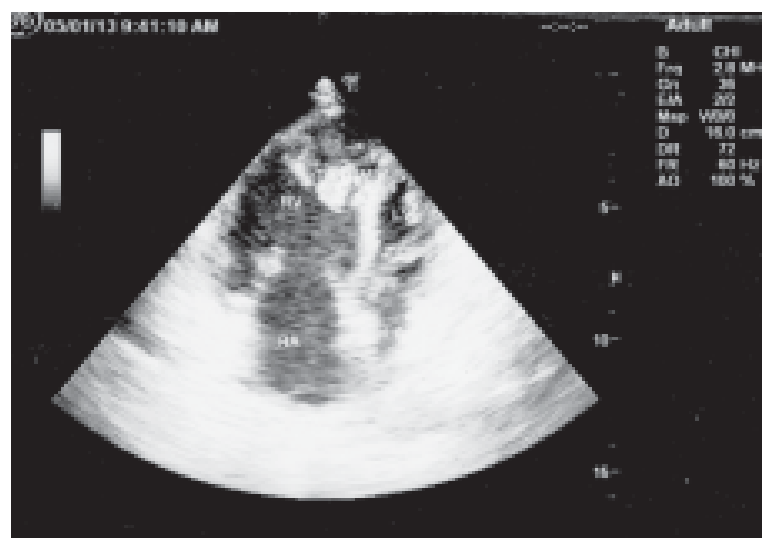

Fig- 1: Apical 4 chamber view shows-Mass in RV apex.

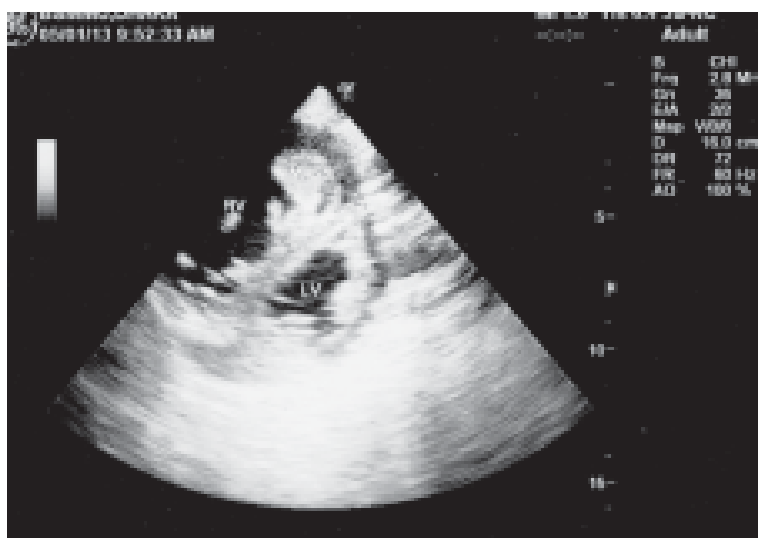

Fig-2: Parasternal Short Axis view Shows Mass in Mid RV. 


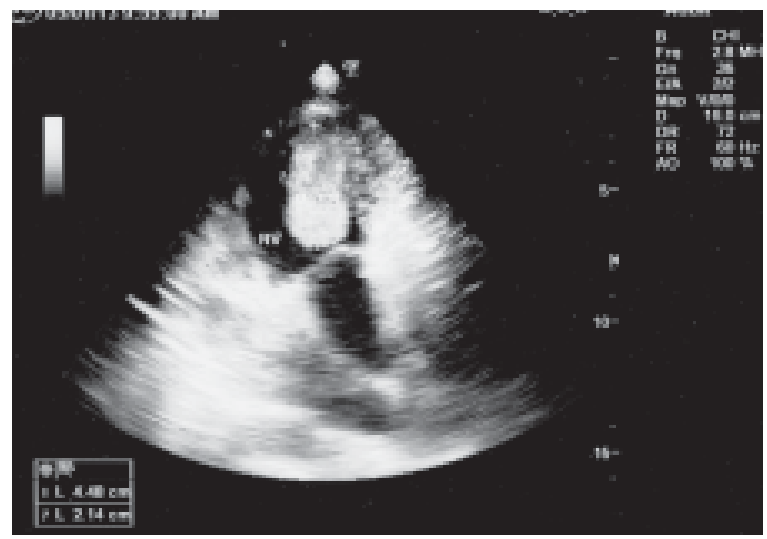

Fig-3: Modified 2-Chamber view shows large mass in RV.

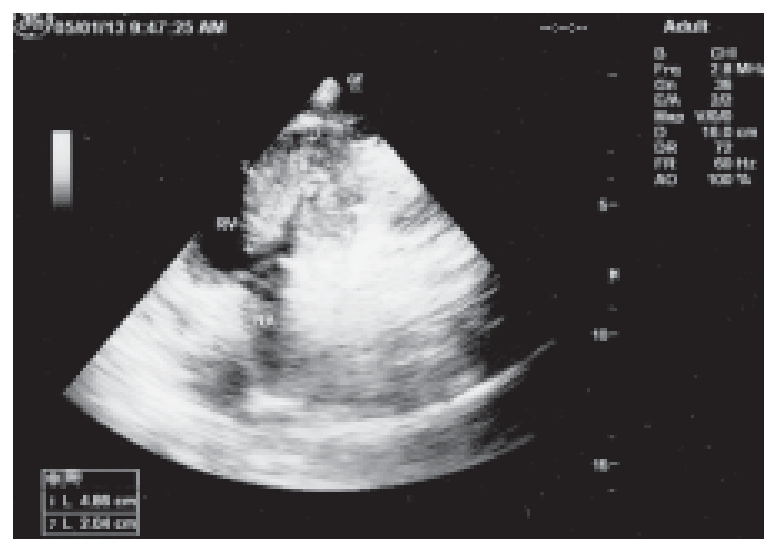

Fig-4: Modified 2-Chamber view shows large mass in RV.

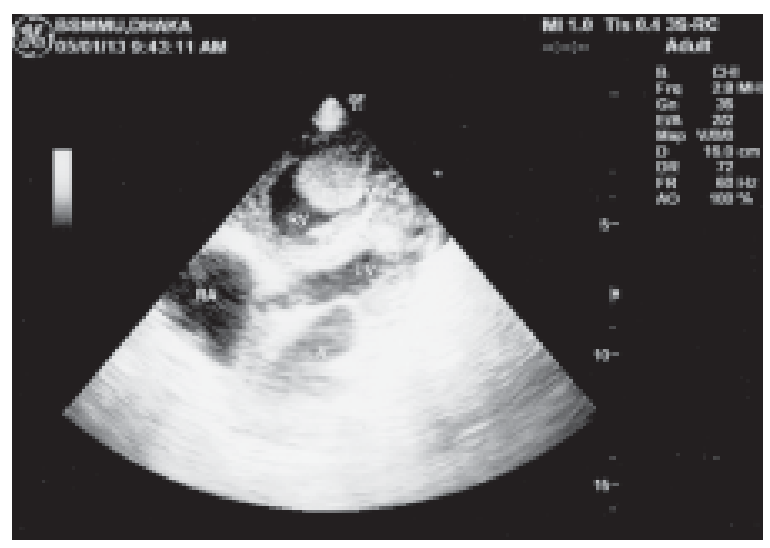

Fig-5: Modified Subcostal view shows globular mass in $R V$.

\section{Discussion:}

Though cardiac tumors are rare condition, among them myxoma are the most common cardiac tumors which is about $88 \% .{ }^{3}$ Commonly found in left atrium. It appears as a sporadic isolated condition in left atrium of middle-aged women with no other pathology. Carney et al have described a special complex group of cardiac myxomas associated to other complex pathology in young people, as "Syndrome myxoma” or "Carney's Syndrome". Reviewing the literature, patients with Carney's syndrome were younger, with a mean age of $26 \mathrm{yrs}$ and female predominance (62\%), cardiac myxoma affected the four chambers of the heart, $64 \%$ in the LA, $44 \%$ the RA, $14 \% \mathrm{LV}$ and $12 \%$ the RV. there were multiple tumors in $41 \%$ and involved more than one chamber in $31 \%$, being synchronous or metachronous. There was a marked familial trend (52\%), a high incidence of recurrence (20\%), with more than one occurring in half the cases. Extra cardiac involvement consisted of 68\% pigmented skin lesions, $40 \%$ cutaneous myxomas, 37\% adrenal cortical disease, 27\% myxoid mammary fibro adenoma and $37 \%$ male patients with testes tumours. A low percentage had pituitary adenoma, melanotic schwannomas and thyroid disease. The diagnosis is made when two or more of these criteria are present. Usually myxoma has peduncles, which attached in atrial septum. As the Myxoma may change it's position with posture change, there may be left inflow obstruction. Patient may complains of shortness of breath, syncope or vertigo during posture change. Variable mitral systolic and diastolic murmurs may be heard. LA myxoma may present with loud first heart sound with opening snap, same signs as mitral stenosis. These patients have unexplained fever with high ESR. Diagnosis can be established by Echocardiography by observing a mass within LA. But in this case there was no feature like mitral stenosis. Her first heart sound was normal but P2 of S2 was loud. Echocardiography confirmed that she has two separate myxomas in right ventricle. There may be a confusions whether they were thrombus or myxomas. But one of the myxoma has peduncle and was moving too and fro which confirms that it was not thrombus. High ESR and finger clubbing are also in favors of myxoma. The treatment of choice of myxoma is surgery. Early diagnosis and promt surgery can avoid complications. ${ }^{5,8}$ Multiple cardiac myxomas are unusal. A case of four tumors in three chambers including both ventricles was reported earlier ${ }^{7}$. During surgery, the four chambers of heart should be examined for atypical myxoma locations, right atriotomy and combined superior trans-septal approach improve exposure of the cavities. ${ }^{4}$ If a patient need valvuloplasty or valve replacement then it can be done at the same time of excision of myxoma. ${ }^{9}$ In autopsy, Myxomas may contain calcification, cysts, areas of hemorrhage, foci of extramedullary hematopoiesis and glands. ${ }^{6}$ Screening of the first degree family members should be conducted, and closed short and long term follow up controls are important. Complex myxoma appears as a multi-systemic disorder, occasionally having an ominous prognosis and 
malignant potentiality, and still undergoing investigation for better understanding and identification. Myxoma can lead to even serious complication like sudden cardiac death. ${ }^{10}$

\section{Conclusion:}

We report this case of multiple myxomas in right ventricle which is a rare entity. Transthorasic echocardiography is enough to diagnose such a case. We can do trans oesophagial echo cardiography to further evaluate about the specific location of myxomas before surgery. To the best of our knowledge it is the first case of multiple myxomas in right ventricle in an adult.

\section{References:}

1. Korkmaz AA, Tamtekin B, Onan B, Demir AS, Guden M, Uckurt Y. Combination of right atrial and left ventricular myxoma. Am Thorac Surg. 2010; 89: 33-5.

2. Konagai N, Cho M, Shigematsu H. Left atrial myxoma associated with acute myocardial infarction and multiple cerebral infarctions: report of a case. Surg Today. 2010;40(12): 1159-63.
3. Piazza N, Chughtai T, Toledano K, Sampalis J, Liao C, Morin JF. Primary cardiac tumors: eighteen years of surgical experience on 21 patients. Can J Cardiol. 2004; 20 : 1443-8.

4. Denguir R, Dhiab M, Meddeb I. Cardiac myxoma. Surgical treatment . About 20 cases. Ann Cardiol Angeiol (Paris). 2006; 55: 49-54. (in French).

5. Reynen K. Cardiac myxomas. N Engl J Med. 1995;333:1610-7.

6. Mc Allister Jr HA, Fenoglio Jr JJ. Tumors of the cardiovascular system. Atlas of tumor pathology. $2^{\text {nd }}$ series. Fascicle 15. Washington. DC: Armed Forces Institute of Pathology; 1978. p. $1-20$.

7. Goal PK, Anand KV, Srivastava AK, Pal L. Multiple cardiac myxoma: report of a rare clinical entity. Indian Heart J. 2002; 54:708-10.

8. Goodwin JF. Diagnosis of the left atrial myxoma. Lancet. 1963;1:464-8.

9. Silverman J, Olwin JS, Graettinger JS. Cardiac myxomas with systemic embolization: review of the literature and report of a case. Circulation. 1962; 26:99-103.

10. Barlis P, Lim EJ, Gow PJ, Seevanayagam S, Calafore P, Cahan RK. Giant cardiac myxoma. Heart Lung Circul. 2007; 16:389-91. 